\title{
RANBP2 Mutation in a Child with Recurrent Acute Necrotizing Encephalopathy
}

\author{
Sung Hye Park, MD, Dong Hyun Kim, MD, Young Se Kwon, MD \\ Department of Pediatrics, Inha University School of Medicine, Incheon, Korea
}

Received: October 23, 2019

Revised: December 26, 2019

Accepted: January 2, 2020

Corresponding author:

Young Se Kwon, MD

Department of Pediatrics, Inha

University School of Medicine, 27

Inhang-ro, Jung-gu, Incheon

22332, Korea

Tel: +82-32-890-3579

Fax: +82-32-890-2844

E-mail:ysped@inha.ac.kr
Acute necrotizing encephalopathy (ANE) is a rare disease characterized by the rapid onset of fever, seizures, and decreased consciousness after a viral infection. Brain magnetic resonance imaging (MRI) of patients with ANE shows the symmetric involvement of the thalami, brainstem, cerebellum, and white matter [1]. Mutations in the Ran-binidng protein 2 (RANBP2) gene are associated with genetic and recurrent ANE [2]. Cases presented in northeast Asia have reported the association of RANBP2 mutations with familial ANE [3]. In the present study, we report a case of a child with ANE who had RANBP2 mutation-associated recurrent ANE.

A 3-year-old girl was admitted to our emergency room because of a seizure that lasted for 30 minutes and rapid loss of consciousness. The patient developed ANE at 11 months of age. At first onset, MRI showed lesions of olive and medial temporal lobe cortex, putamen, external capsule, and medial thalamus (Fig. 1A-C). However, her health improved and she did not develop any complications since this episode of ANE. Five days before the emergency room visit, the girl developed a fever of up to $40^{\circ} \mathrm{C}$. One day before the admission, the girl experienced general weakness and episodes of vomiting. Neurological examination of the patient showed an increased motor tone, positive bilateral Babinski reflexes, and decorticate posturing. Blood biochemical analysis showed a white blood cell count of $3 \times 10^{6} / \mathrm{L}$, and C-reactive protein level of 0.3 $\mathrm{mg} / \mathrm{dL}$. Polymerase chain reaction analysis of respiratory sample of the patient indicated the presence of a rhinovirus infection. Cerebrospinal fluid (CSF) analysis indicated a protein level of 57.5 $\mathrm{mg} / \mathrm{dL}$, and glucose level of $69 \mathrm{~mL} / \mathrm{dL}$, with a normal CSF pressure and white blood cell count. Brain MRI showed hypointense signals on T1-weighted images and hyperintense signals on T2-weighted images of the thalamus, hypothalamus, midbrain, pons, and medulla (Fig 1D-F), which were similar to those observed during the previous ANE episode. In particular, it was confirmed that thalamus lesions occurred at sites similar to the previous lesions (Fig. 1F). Results of sleep electroencephalography indicated an abnormal sleep record because of slightly suppressed background activities. The patient was initially administered intravenous methylprednisolone therapy, which was tapered over 4 weeks, along with antibiotic (ceftriaxone and vancomycin) and antiviral (acyclovir) therapy. The initial dose of methylprednisolone started at $30 \mathrm{mg} / \mathrm{kg} /$ day. Three days after starting dose, the dose was reduced by half of the initial dose.

Brain MRI performed after 1 month showed improvement in the clinical signs of ANE. However, the cognitive and motor functions of the patient did not improve. Next, a genetic test was

Copyright(C) 2020 Korean Child Neurology Society

This is an Open Access article distributed under the terms of the Creative Commons Attribution Non-Commercial License (http://creativecommons.org/licenses/by-nc/4.0/) which permits unrestricted non-commercial use, distribution, and reproduction in any medium, provided the original work is properly cited. 


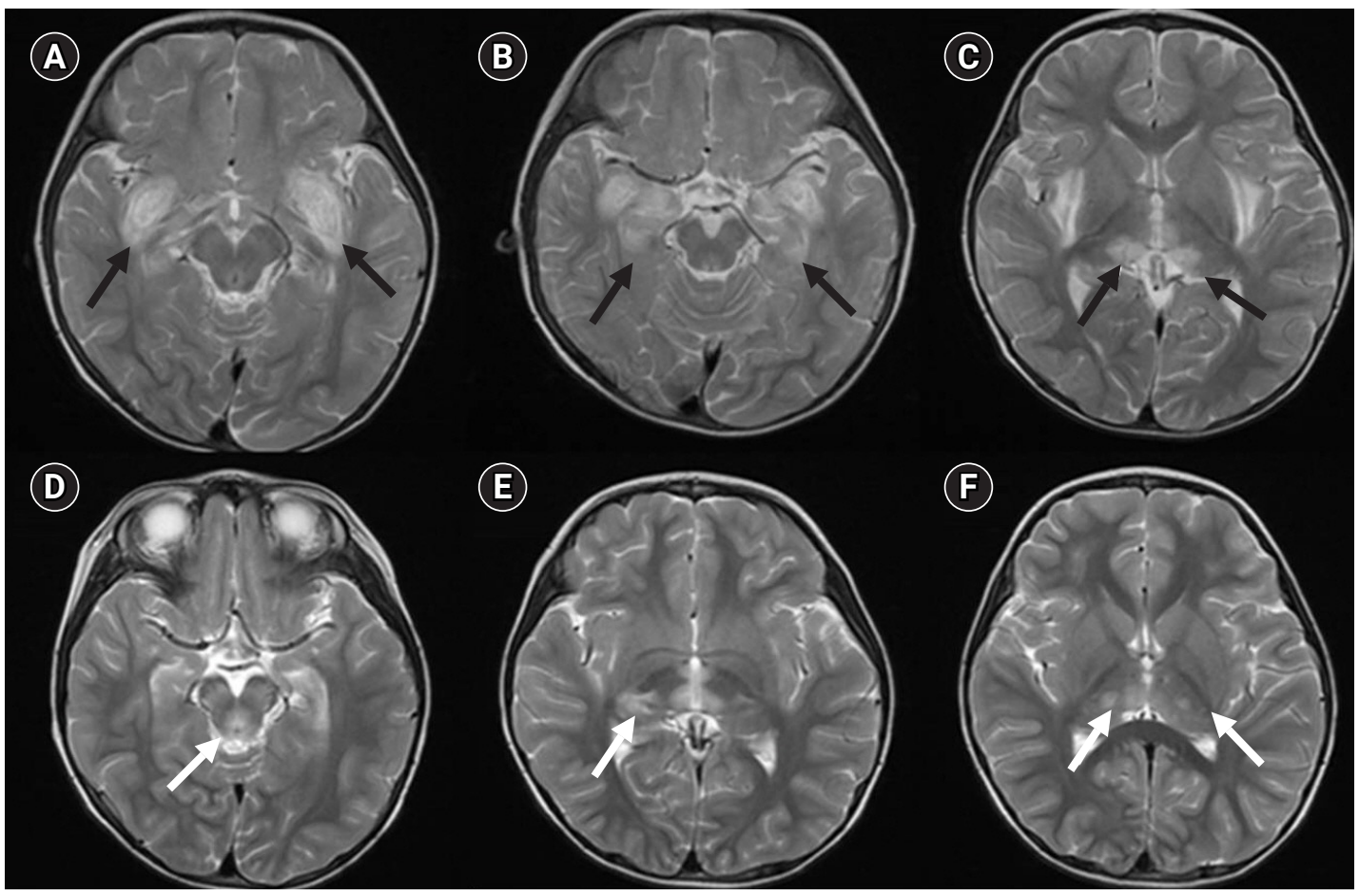

Fig. 1. $(A, B, C)$ Brain magnetic resonance imaging (MRI) of the first ANE episode showing the involvement of the pyramid and olive and that of the medial temporal lobe cortex, putamen, external capsule, and medial thalamus (black arrows). (D, E, F) The brain MRI of second ANE episode showing symmetric T2 hyperintense signals in the midbrain, bilateral pons and thalamus (white arrows).

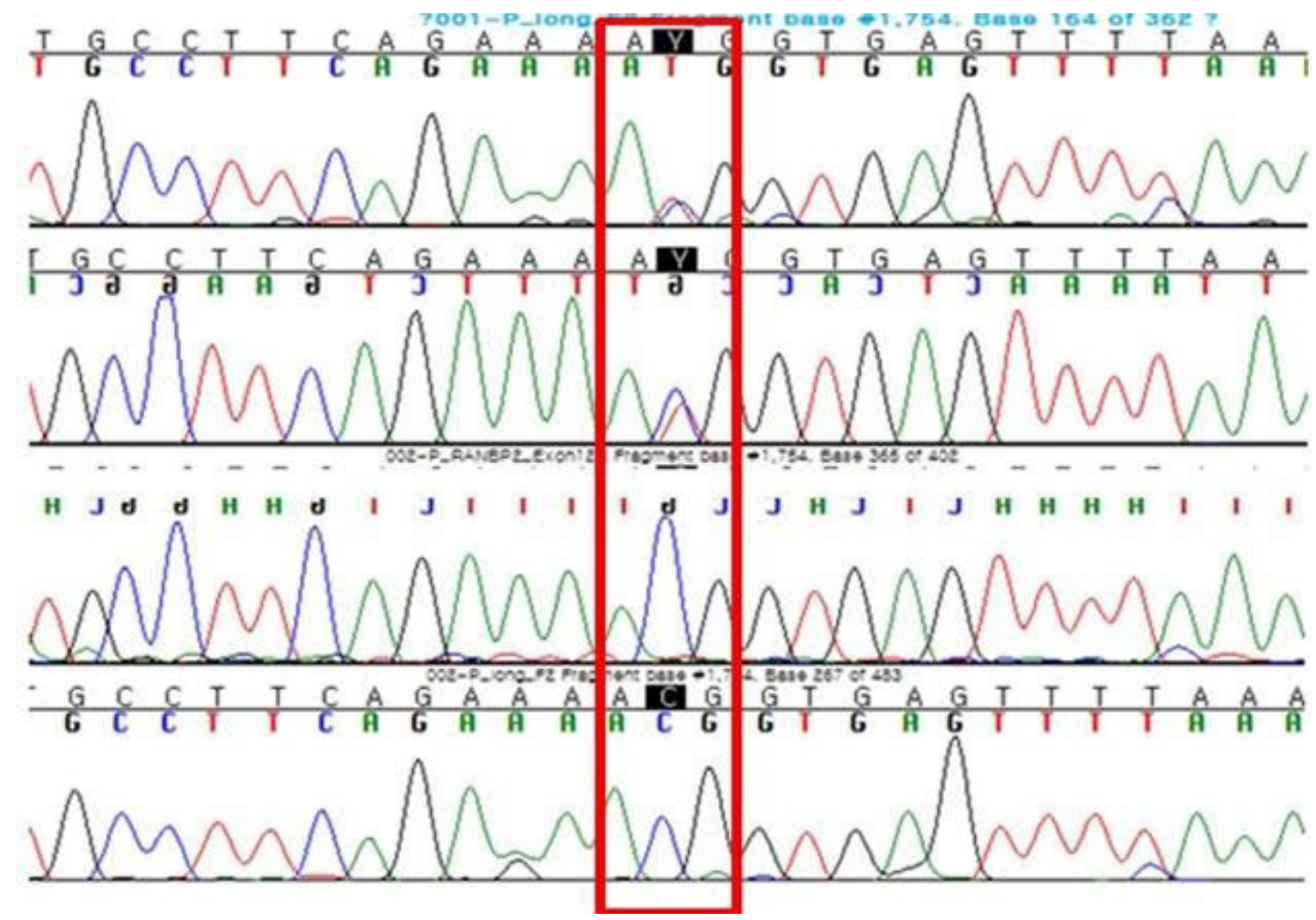

Fig. 2. Electropherogram of our case showing the mutated allele, compared with the results of whole-exome sequencing. This mutation (Thr585Met) affects an amino acid residue. 
performed to investigate the recurrent hypo- and hyperintense signals observed on the T1- and T2- weighted MRI. Results of the genetic test showed that the patient had an RANBP2 mutation (c.1754C > T, p.Thr585Met), which was absent in her father and mother (Fig. 2). At present, the patient is undergoing rehabilitation therapy. She have not showed further seizure attack without any medication of antiepileptic drug.

Neurologic prognosis is associated with the number of seizure attacks [4]. Studies have reported that approximately $40 \%$ complications persist after the administration of steroid treatment in the initial stage of diagnosis. Moreover, recent studies have reported that prognosis is associated with the timing of diagnosis and treatment administration and the involvement of the brain stem [5].

In conclusion, patient with symptoms such as fever, seizure, and rapid consciousness loss after a viral infection and showing the clinical signs of typical ANE on brain MRI should receive early steroid treatment and should be examined for the presence of RANBP2 mutations.

\section{Conflicts of interest}

No potential conflict of interest relevant to this article was reported.

\section{ORCID}

Sung Hye Park, https://orcid.org/0000-0002-2945-612X

Young Se Kwon, https://orcid.org/0000-0003-4570-7037

\section{Author contribution}

Conceptualization: SHP and YSK. Writing-review \& editing: SHP and DHK.

\section{References}

1. Mizuguchi M, Abe J, Mikkaichi K, Noma S, Yoshida K, Yamanaka $\mathrm{T}$, et al. Acute necrotising encephalopathy of childhood: a new syndrome presenting with multifocal, symmetric brain lesions. J Neurol Neurosurg Psychiatry 1995;58:555-61.

2. Neilson DE, Adams MD, Orr CM, Schelling DK, Eiben RM, Kerr DS, et al. Infection-triggered familial or recurrent cases of acute necrotizing encephalopathy caused by mutations in a component of the nuclear pore, RANBP2. Am J Hum Genet 2009;84:44-51.

3. Lee YJ, Hwang SK, Lee SM, Kwon S. Familial acute necrotizing encephalopathy with RANBP2 mutation: the first report in Northeast Asia. Brain Dev 2017;39:625-8.

4. Lee JH, Lee M, Lee J. Recurrent acute necrotizing encephalopathy in a Korean child: the first non-Caucasian case. J Child Neurol 2012;27:1343-7.

5. Okumura A, Mizuguchi M, Kidokoro H, Tanaka M, Abe S, Hosoya $\mathrm{M}$, et al. Outcome of acute necrotizing encephalopathy in relation to treatment with corticosteroids and gammaglobulin. Brain Dev 2009;31:221-7. 